\title{
HYPERSPECTRAL SPECTROSCOPY TO DETECT DIFFERENT RESPONSES OF TWO SOYBEAN (GLYCINE MAX) CULTIVARS TO CHARCOAL ROT (MACROPHOMINA PHASEOLINA) TOXIN
}

\author{
Ameer Al-Ahmadi ${ }^{*}$, Arjun Subedi ${ }^{2}$, Ruplal Choudhary ${ }^{2}$, \\ Ahmad Fakhoury ${ }^{2}$, Dennis Watson ${ }^{2}$
}

\footnotetext{
${ }^{1 *}$ Corresponding author. Department of Agricultural Machines and Equipment, College of Agricultural Engineering Sciences, University of Baghdad/ Baghdad, Iraq.

Email: ameer.alahmadi@coagri.uobaghdad.edu.iq | ORCID ID: https://orcid.org/0000-0002-9046-9990
}

\section{KEYWORDS}

hyperspectral spectroscopy, Glycine Max, charcoal rot, ratio, reflectance.

\begin{abstract}
Previous studies have confirmed the potential of hyperspectral spectroscopy (HS) to detect charcoal rot toxin effect on soybean (Glycine max). However, there is no evidence that it can differentiate among difference responses to that effect. This research tested the potential of HS (900-2400 nm) to differentiate different responses to charcoal rot effect caused by the fungal pathogen Macrophomina phaseolina. Known susceptible 'Pharaoh' and resistant 'Spencer' cultivars of soybean seedlings at the V1 stage were tested, and HS reflectance was measured in each treatment at $0 \mathrm{~h}$ (just before toxin treatment), $24 \mathrm{~h}$, and $36 \mathrm{~h}$ after toxin treatment. For both cultivars, reflectance generally decreased up to $10 \%$ over time for controls and increased for treated seedlings up to $22 \%$. Pharaoh had significant increases in reflectance 24 and $36 \mathrm{~h}$ after treatment, while Spencer did not exhibit significant changes in reflectance over the 24 and 36-h periods. The ratio of Al-Ahmadi et al. (2018) was also evaluated. Spencer showed a higher ratio than Pharaoh. Based on our results, HS can be used to compare the relative resistance of soybean cultivars to charcoal rot and is a potential screening technique to classify soybean cultivars based on their resistance to charcoal rot toxin.
\end{abstract}

\section{INTRODUCTION}

Soybean (Glycine max) is one of the most valuable crops, with a wide range of uses due to its protein and oil content (Lee et al., 2019). Soybean can be affected by charcoal rot without any clear early symptoms (Meyer, 1974). Noticeable symptoms of charcoal rot, characterized mainly by wilting, may be missed until the maturity stage R5 (Mengistu et al., 2011), with reddish-brown lesions on lower stems being obvious at stages R7 or R8 (Pearson, 1984).

Charcoal rot threatens many crops and leads to substantial yield losses. It is caused by the fungus Macrophomina phaseolina (Tassi) Goid, a soil-borne and seed-borne pathogen (Coser et al., 2017) that attacks plants via their root systems (Hemmati et al., 2018), causing wilting symptoms. This pathogen tends to be more active under hot and dry conditions (Nagasubramanian et al., 2018).
Some adopted preventive methods to control charcoal rot, such as crop rotation, mechanical treatments such as tillage, irrigation control, fertilization using specific nutrients, and fungicide application, can partly help in controlling this disease (Luna et al., 2017). However, these methods may have limited effectiveness without adopting the most resistance cultivar (Coser et al., 2017; Luna et al., 2017; Nagasubramanian et al., 2018).

Sensors are considered feasible tools to detect changes in plants due to stress caused by diseases and may evaluate the intensity of such stresses (Mahlein, 2016). Hyperspectral spectroscopy (HS) is the use of sensors for disease detection, such as powdery mildew in wheat (Haider Khan et al., 2018), yellow rust and fusarium head blight in wheat and barley (Whetton et al., 2018), brown rust and yellow rust on wheat leaves (Bohnenkamp et al., 2019), and late blight in potato (Gold et al., 2019). This approach has also been used with charcoal rot in soybean by relating the

\footnotetext{
${ }^{2}$ Department of Plant Soil and Agricultural Systems, Southern Illinois University/ Illinois, USA.
} 
reflectance of ground roots and stems from mature plants at stages R7.2 and R7.8 to microsclerotia density in soybean tissue (Fletcher et al., 2014). A different study of HS of soybean stems used seedlings inoculated with $M$. phaseolina; HS image data in the range of 383-1032 nm were collected and reduced to six wavebands with a binary classification accuracy of $97 \%$ for identification of charcoal rot disease in seedlings (Nagasubramanian et al., 2018).

In another study, the reflectance of leaves of a single 'Pharaoh' soybean cultivar in the 900-2400-nm range using HS was used to detect differences in soybean seedlings (V1 stage; without roots) exposed to charcoal rot toxins compared to non-treated seedlings, with increasing reflectance for seedlings exposed to the toxins (Al-Ahmadi et al., 2018). A ratio of reflectance prior to toxin exposure to reflectance measurement $24 \mathrm{~h}$ later has been proposed, with lower ratios indicating a higher sensitivity to toxins produced by M. phaseolina (Al-Ahmadi et al., 2018). The proposed ratio was based on a single soybean cultivar and requires testing with known relatively susceptible and resistant soybean cultivars to determine if the responses measured by HS are different among cultivars.

The purpose of this study was to apply the measurement method recommended by Al-Ahmadi et al. (2018) and evaluate it with known susceptible and resistant soybean cultivars to see if the method can detect differences in the cultivar response to charcoal rot toxin, indicating the potential of this methodology to be used in screening to identify soybean cultivar resistance to M. phaseolina at the early growth stage (V1).

\section{MATERIAL AND METHODS}

\section{Soybean Seedling Preparation}

Soybean (Glycine max) cultivars 'Pharaoh' and 'Spencer' were used in this study. 'Pharaoh' is considered highly susceptible (Pawlowski et al., 2015; Nagasubramanian et al., 2018) and 'Spencer' relatively resistant to charcoal rot (Twizeyimana et al., 2012). The study was conducted in plant pathology laboratories at the Southern Illinois University, Carbondale, Illinois. Two containers were prepared with soil for each cultivar. Seeds of the corresponding cultivar were planted in each container, and the containers were placed in a growth chamber at approximately $30^{\circ} \mathrm{C}$ and $45 \%$ relative humidity. Containers were checked regularly and watered as needed. At the V1 growth stage (Fehr et al., 1971), 16 seedlings of uniform leaf size of each cultivar were selected and randomly divided into two groups of eight seedlings each for control (non-treated) and toxin-treated seedlings. The number of seedlings for this experiment was a compromise to keep the measurement time below 3 hours while following the same measurement protocol as Al-Ahmadi et al. (2018), as the HS measurement of 30 replicates was estimated to require over 11 hours for each measurement event at 12-hour intervals. Our use of 8 replicates was comparable to other studies using 3 (Cao et al., 2015), 4 (Nagasubramanian et al., 2018), and 10 (Fletcher et al., 2014) replicates.

On the afternoons prior to the measurements, a 30$\mathrm{ml}$ vial for each plant was filled ( $75 \%$ full) with tap water and labeled to identify the cultivar, treatment, and replicate number. A stem from each plant, with five leaves and consistent length, was separated and placed in vials. One leaf from each plant was arbitrarily identified by placing a small sticker around each stem under the two top leaves with its extension pointing to the identified leaf, ensuring that the same leaf was sampled for each measurement. A random order was used to place vials for subsequent HS measurements. Cut seedlings were allowed to reach equilibrium water content by leaving them in the water-filled vials overnight $(12 \mathrm{~h}$ ) before proceeding with the experiment.

\section{Charcoal Rot Toxin Preparation and Application}

An isolate of $M$. phaseolina, collected from a soybean field in southern Illinois, was used to prepare the fungal toxin in our experiment. Potato dextrose agar (PDA) was used to grow the fungus at room temperature. After 1 week, plugs (10 of 2-mm diameter) of fungal mycelia were removed from PDA plates and placed in $500 \mathrm{ml}$ of Czapek Dox broth medium for 2 weeks at $25-30^{\circ} \mathrm{C}$. Fungal extract and fungal mycelia were then filtered using a Miracloth (Calbiochem, La Jolla, CA), and the filtrate was stored at $4^{\circ} \mathrm{C}$. For this study, the filtrate was diluted to a $50 \%$ solution with distilled water. After the initial $(0 \mathrm{~h}) \mathrm{HS}$ measurement of each seedling marked for the toxin treatment, water was removed from the vial and replaced with the toxin solution. Although this method was consistent with Al-Ahmadi et al. (2018), the relative toxicity of the solution could vary from that of the prior study. Since the assay was based on the presence of toxic compounds (some possibly not yet identified) produced by the fungus and present in the fungal filtrate, we did not have absolute measurements of the concentration of the fungal toxins.

\section{HS Spectrometer}

The HS spectrometer (NIR256-2.5, Ocean Optics, Dunedin, FL USA) selected for this study was based on an InGaAs linear image sensor (G9208-256W, Hamamatsu Photonics, Hamamatsu City, Japan). Specifications indicated a spectral range of $900-2500 \mathrm{~nm}$ in the NIR region, with a signal-to-noise ratio of 4000:1 and an average spectral resolution of $7 \mathrm{~nm}$. This spectral range was preferred over a 340-1000-nm sensor, based on a prior study (Al-Ahmadi et al., 2018). The radiation source was tungsten halogen (HL-2000, Ocean Optics, Dunedin, FL, USA) with a spectral range of 360-2400 nm, which slightly reduced the effective range of the sensor system to 900 $2400 \mathrm{~nm}$. A measuring probe (QR400-7-VIS-BX, Ocean Optics, Dunedin, FL, USA) with a $6.35 \mathrm{~mm}$ diameter was connected to the HL-2000 via fiber optics and secured to a reflection probe holder (RPH-1, Ocean Optics, Dunedin, FL, USA) at $45^{\circ}$. Ambient light sources were blocked by the probe holder from reaching the probe. Data acquisition software (SpectraSuite 2.0.162, Ocean Optics, Dunedin, FL, USA) was used to control the spectrometer for data collection. The spectrometer signal was calibrated with a Spectralon ${ }^{\circledR}$ diffuse reflectance standard (WS-1, Ocean Optics, Dunedin, FL, USA), with reflectivity of more than $96 \%$ for the spectral range. Calibration resulted in a nearly consistent reflectance value of $100 \%$ across the spectral range and was repeated before each seedling was measured.

\section{Data Collection}

Hyperspectral data over the spectral range of 900 $2400 \mathrm{~nm}$ were collected from two locations on each of the two leaves from each seedling. While no differences among leaves or locations of the same seedling were readily visible, 
the four measurements were averaged to moderate any differences. The leaves located directly under the two or three uppermost leaves of the selected seedling were selected for HS measurements. Two consistent locations per leaf for a total of 4 measurements per seedling and 128 measurements per measurement event were recorded. For measurement, each leaf was positioned on a black foam board (mean reflectance of $0.19 \pm 0.13$ ) to diminish possible background reflectance of light transmitted through the leaf (Fig. 1). Only the adaxial face of leaves was used for HS measurements. The HS probe holder with the probe was placed in direct contract on the same approximate location on each leaf for each measurement. Leaf locations for measurement were between the first and second lateral veins from the base and the second and third lateral veins from the apex, with all measurements taken at the midpoint between the midrib and the margin on the right side of the leaf as viewed with the apex up (Fig. 1). Seedlings were handled with nitrile gloves, and all seedlings received the same amount of handling.

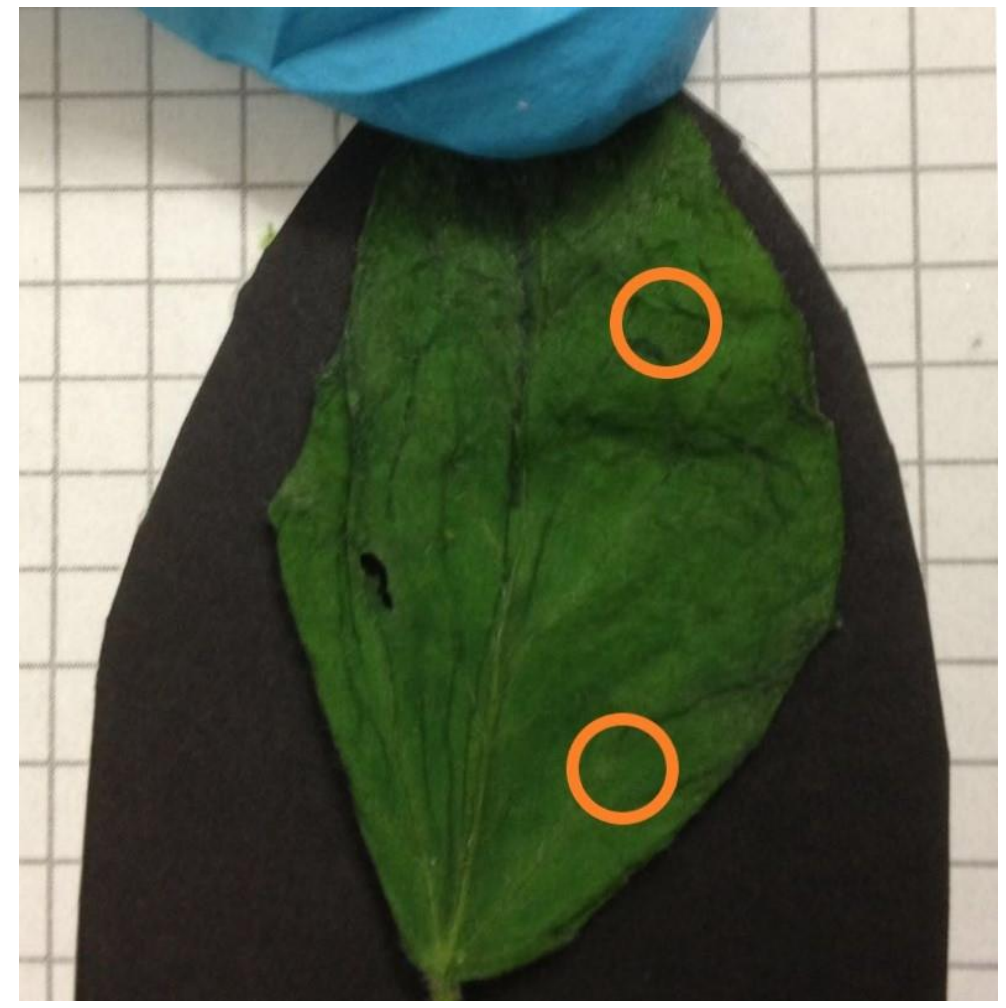

FIGURE 1. Layout of leaf on black foamboard for hyperspectral measurement. Circles indicate location of measurements on each leaf.

Hyperspectral data were collected at measurement events of 0 -h (immediately before toxin treatment), 24-h, and 12-h intervals thereafter as long as all the leaves could be handled without tearing. For this study, measurements were terminated after $36 \mathrm{~h}$ due to severe wilting of many of the leaves. All leaves were measured in the same order at each measurement event, ensuring that each leaf had the same period of toxin exposure.

\section{Hyperspectral Data Preprocessing}

Raw data for each HS measurement consisted the average of 10 successive scans. All measurements were organized in a spreadsheet for further preprocessing. All wavelengths were rounded to the nearest $10 \mathrm{~nm}$ for consistency with the prior study (Al-Ahmadi et al., 2018), and all wavelengths with the same rounded $\mathrm{nm}$ value were averaged, resulting in 151 wavebands of $10 \mathrm{~nm}$ width for further analysis.

\section{Data Analysis}

The average reflectance of the four locations (two leaves per seedling, two locations per leaf) for each seedling represented an experimental unit. There were eight replicates per treatment for each cultivar at each measurement event. One-way analysis of variance (ANOVA; alpha $=0.05$ ) was performed to analyze reflectance data of each waveband (Mo et al., 2017; Wang et al., 2019) between control cultivars, between toxintreated cultivars, and among measurement events for each toxin-treated cultivar. Fisher's least significant difference (LSD) test was used to determine differences among the three measurement events when ANOVA indicated significant differences. We used SAS Enterprise Guide 7.1 (SAS Institute Inc., Cary, NC, 1982) to perform ANOVA and the LSD test.

\section{RESULTS AND DISCUSSION}

\section{Baseline Reflectance}

Baseline HS results at $0 \mathrm{~h}$ (before any seedlings were exposed to charcoal rot toxins) revealed no significant differences at any wavebands between control and subsequently toxin-treated seedlings for either Pharaoh $\left(F_{(1,14)}, p>0.22\right)$ or Spencer $\left(F_{(1,14)}, p>0.18\right)$ cultivars. These results indicate relatively consistent reflectance spectra of the seedlings, within each cultivar, prepared for control and toxin treatments. When the spectra of control and subsequently toxin-treated seedlings at $0 \mathrm{~h}$ were 
combined, there were significant differences $\left(F_{(1,30)}, p<\right.$ 0.05 ) between cultivars in the 1360-2400-nm waveband range (Fig. 2). The Pharaoh cultivar had a higher reflectance than the Spencer cultivar, with a difference in mean reflectance peaking at less than three percentage points (pp) and with a mean of $1.54 \pm 0.95 \mathrm{pp}$, which is less than the differences noted at later measurement times. These baseline reflectance differences of untreated seedlings can be attributed to genetic or chemical differences between the cultivars (Porker et al., 2017; Wee et al., 2018), which were expressed in reflectance of the 1360-2400 $\mathrm{nm}$ range.

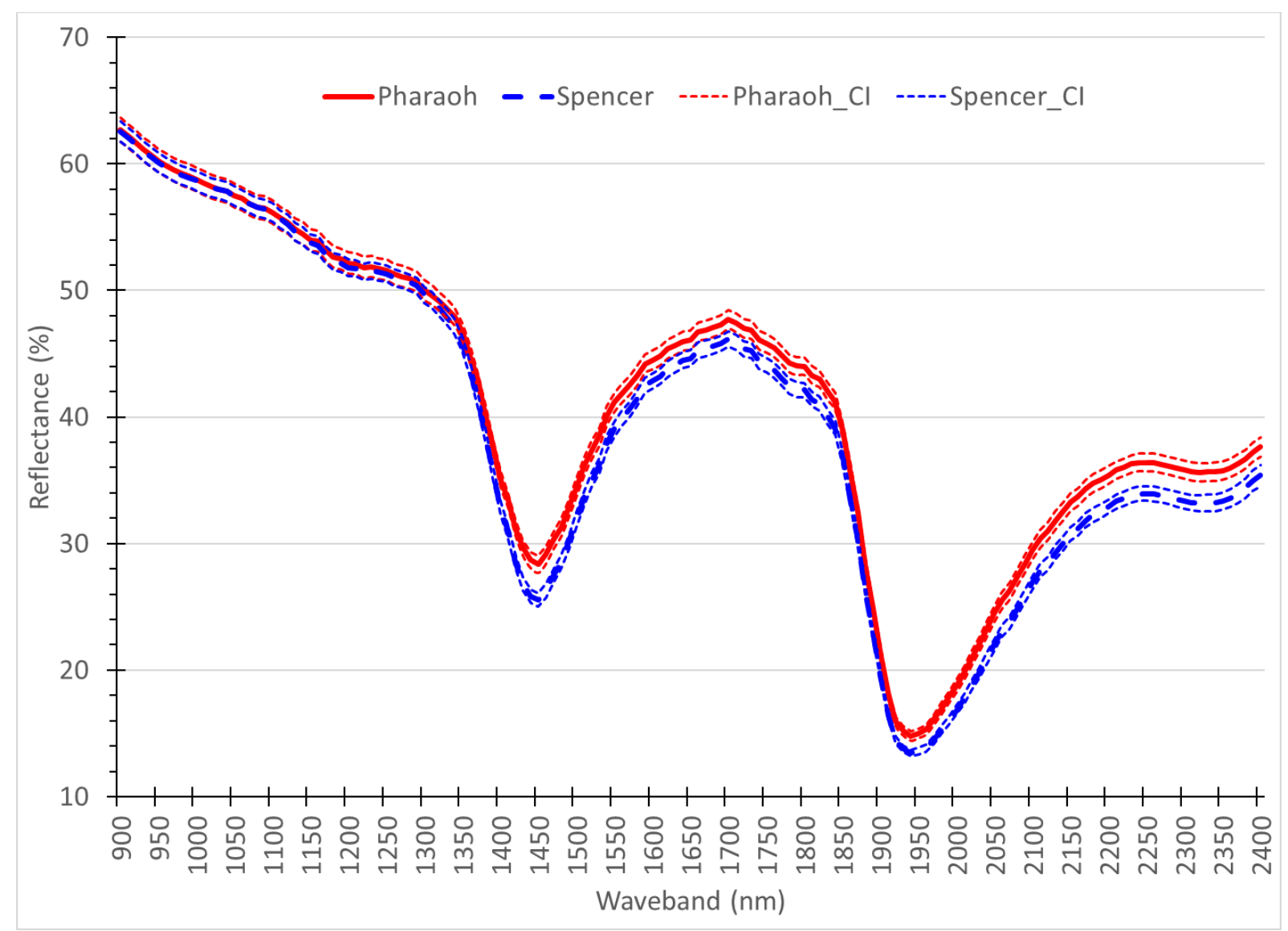

FIGURE 2. Mean reflectance spectra, with $95 \%$ confidence intervals, of Pharaoh and Spencer cultivars at 0 h (prior to toxin treatment).

\section{Spectral Changes of Control Seedlings}

Control (non-toxin-treated) seedlings showed highly significant $\left(F_{(2,21)}, p<0.01\right)$ spectral changes over time $(0$, 24 , and $36 \mathrm{~h}$ ) for each waveband across the entire 900-2400 $\mathrm{nm}$ spectrum for both Pharaoh and Spencer (Fig. 3). For both cultivars, there were no significant differences between the 24-h and 36-h measurement events, although the 36-h reflectance was generally lower than the 24-h reflectance. For both cultivars, the 0 -h reflectance measurements were significantly higher than the later measurements. This behavior may be attributed to different water contents of the seedlings over time (higher water content at $24 \mathrm{~h}$ ), affecting the reflectance within the NIR region (Bauer, 1985; Hunt \& Rock, 1989; Diourte et al., 1995; Hennessy et al., 2020). The similarity between the spectral curves of the $24-\mathrm{h}$ and $36-\mathrm{h}$ measurements may be due to seedling saturation with water, causing no difference in reflectance.

Over time, there was some decrease in the waveband ranges at which the cultivars (non-treated controls) were significantly different from each other, in comparison to the 1360-2400 $\mathrm{nm}$ range at $0 \mathrm{~h}$ (Fig.. 3). At $36 \mathrm{~h}$, the significantly different $\left(F_{(1,14)}, p<0.05\right)$ wavebands were 1400-1540 nm and 1850-2370 nm. At both 24 and $36 \mathrm{~h}$, reflectance of Pharaoh was slightly higher than that of Spencer, which may be attributed to genetic or chemical differences between the two cultivars (Porker et al., 2017; Wee et al., 2018). However, the mean decrease in reflectance for the Pharaoh and Spencer cultivars from 0 to $36 \mathrm{~h}$ was $4.16 \pm 1.18 \mathrm{pp}$ and $3.47 \pm 0.97 \mathrm{pp}$, respectively. This decrease in reflectance of the control seedlings over time was consistent with Al-Ahmadi et al. (2018) and in contrast to the reaction of toxin-treated seedlings. 


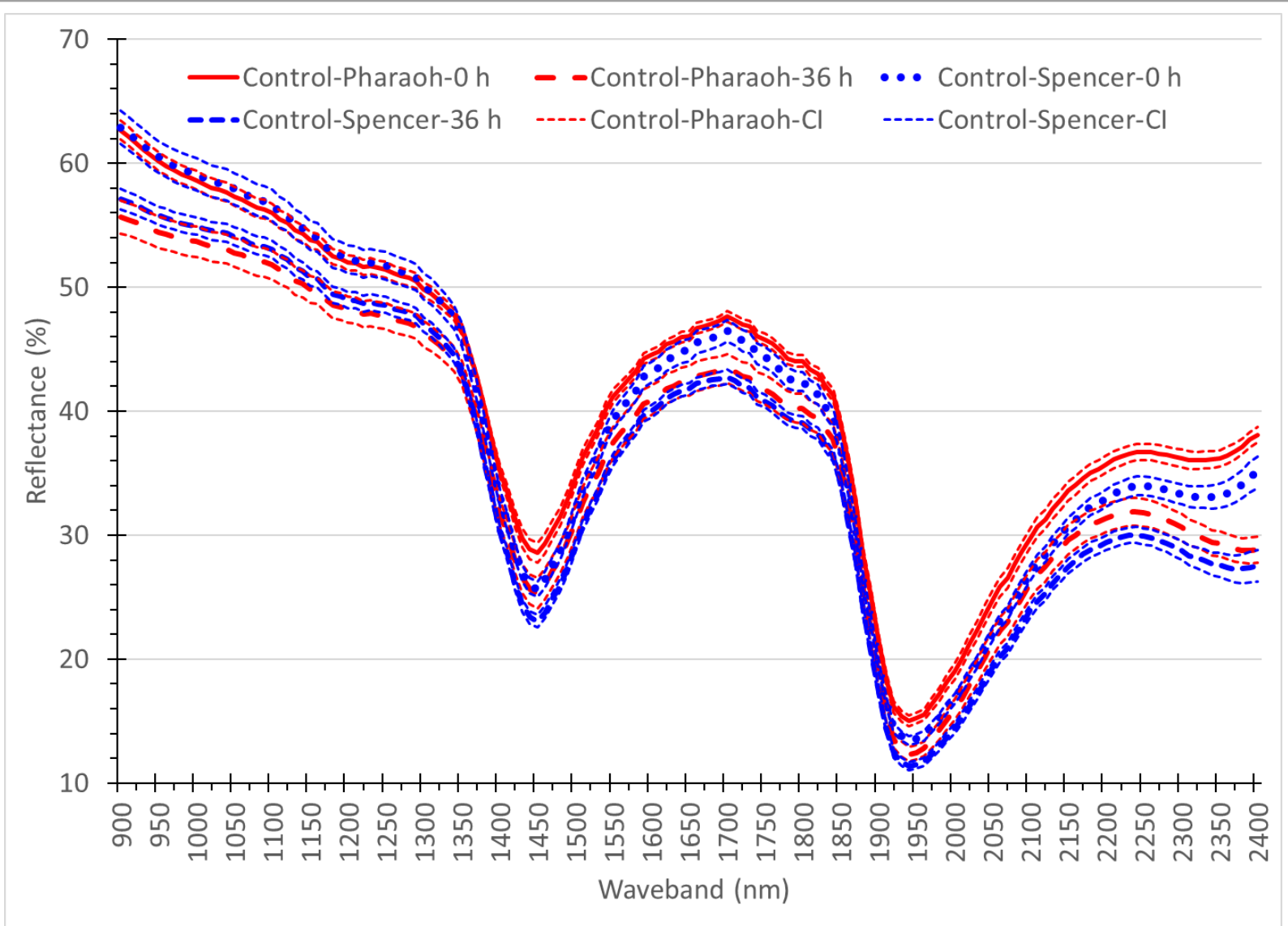

FIGURE 3. Comparison of mean reflectance spectra, with 95\% confidence intervals (CI), of Pharaoh and Spencer cultivars at 0 h, $24 \mathrm{~h}$, and $36 \mathrm{~h}$.

\section{Spectral Changes of Toxin-Treated Seedlings}

Pharaoh seedlings were affected by the toxin, but there was a variation in the response, as seen in Figure 4 and reflected by the wider error bands in Figure 5 for 36 $\mathrm{h}$. There were noticeable changes in visual seedling health (Fig. 4), and reflectance increased across the entire 900$2400 \mathrm{~nm}$ range as exposure time to the toxin solution increased (Fig. 5).

A prior study (Al-Ahmadi et al., 2018) suggested the maximum HS reflectance and ratio differences between treated and non-treated seedlings would occur just before the leaves were too wilted to handle, which occurred after $24 \mathrm{~h}$ post-toxin treatment. In this study, the seedlings could be handled an additional $12 \mathrm{~h}$ or a total of $36 \mathrm{~h}$ after treatment.
Time differences may be indicative of the rate at which toxic compounds form in different preparations of the fungal solution. Since some of the toxic compounds may yet be unknown, a specific "count" of toxin strength is not practical. Rather than a specific treatment time, the original recommendation of Al-Ahmadi et al. (2018) to measure reflectance before leaves are too wilted to handle without tearing is still the best recommendation. This may require some experience and checking leaves at set time intervals to be able to complete measurements before they are too wilted.

The differences between reflectance at $36 \mathrm{~h}$ and $0 \mathrm{~h}$ or $24 \mathrm{~h}$ were highly significant $\left(F_{(2,21)}, p<0.01\right)$ across the entire spectrum. In the ranges of $1140-1870 \mathrm{~nm}$ and 2060 $2240 \mathrm{~nm}$, reflectance at $24 \mathrm{~h}$ was also significantly $\left(F_{(2,21)}\right.$, $p<0.01$ ) higher than that at $0 \mathrm{~h}$. 


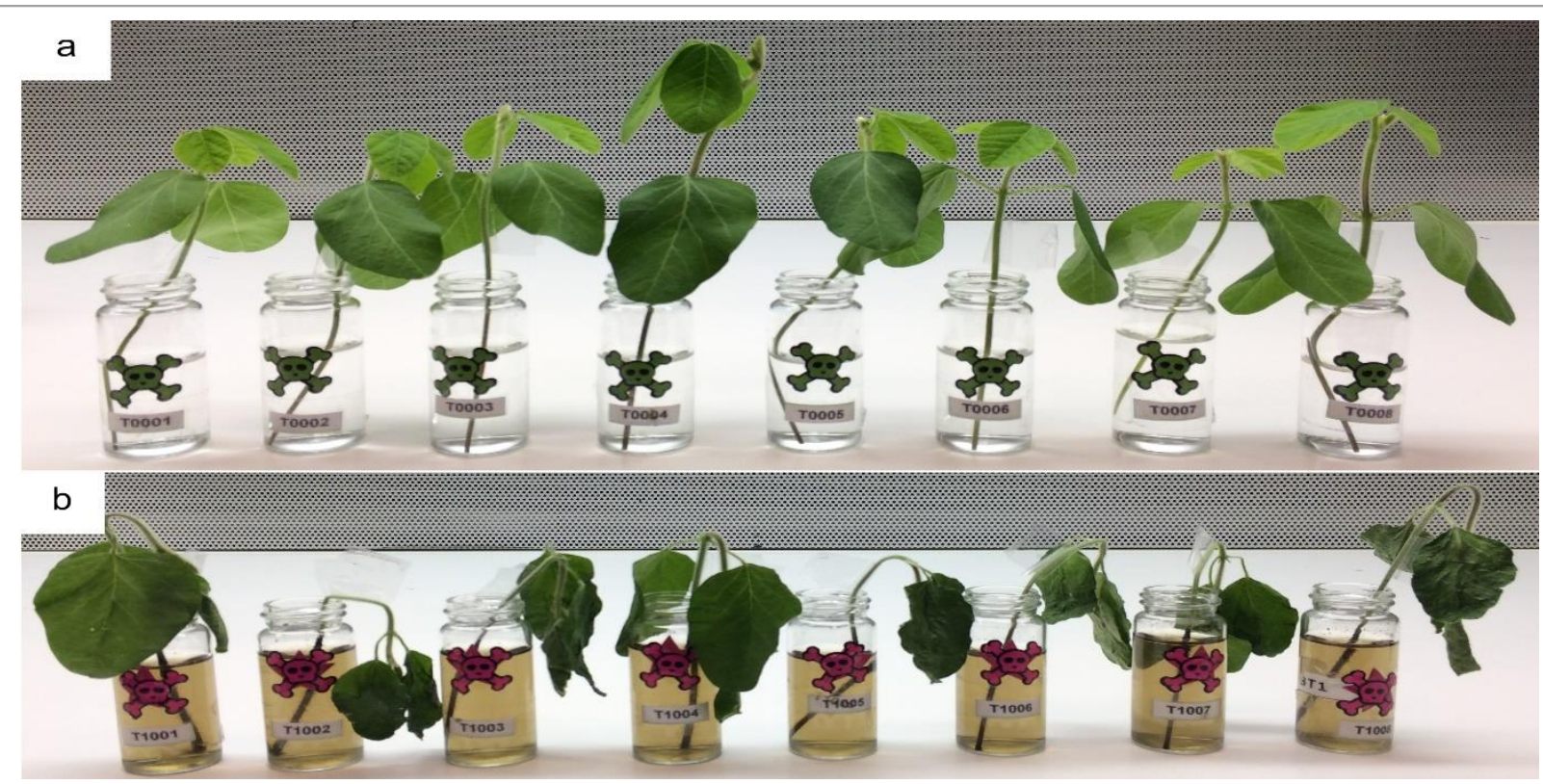

FIGURE 4. Pharaoh cultivar at $36 \mathrm{~h}$ after toxin treatment illustrating the relative health of a) controls and b) toxin-treated seedlings.

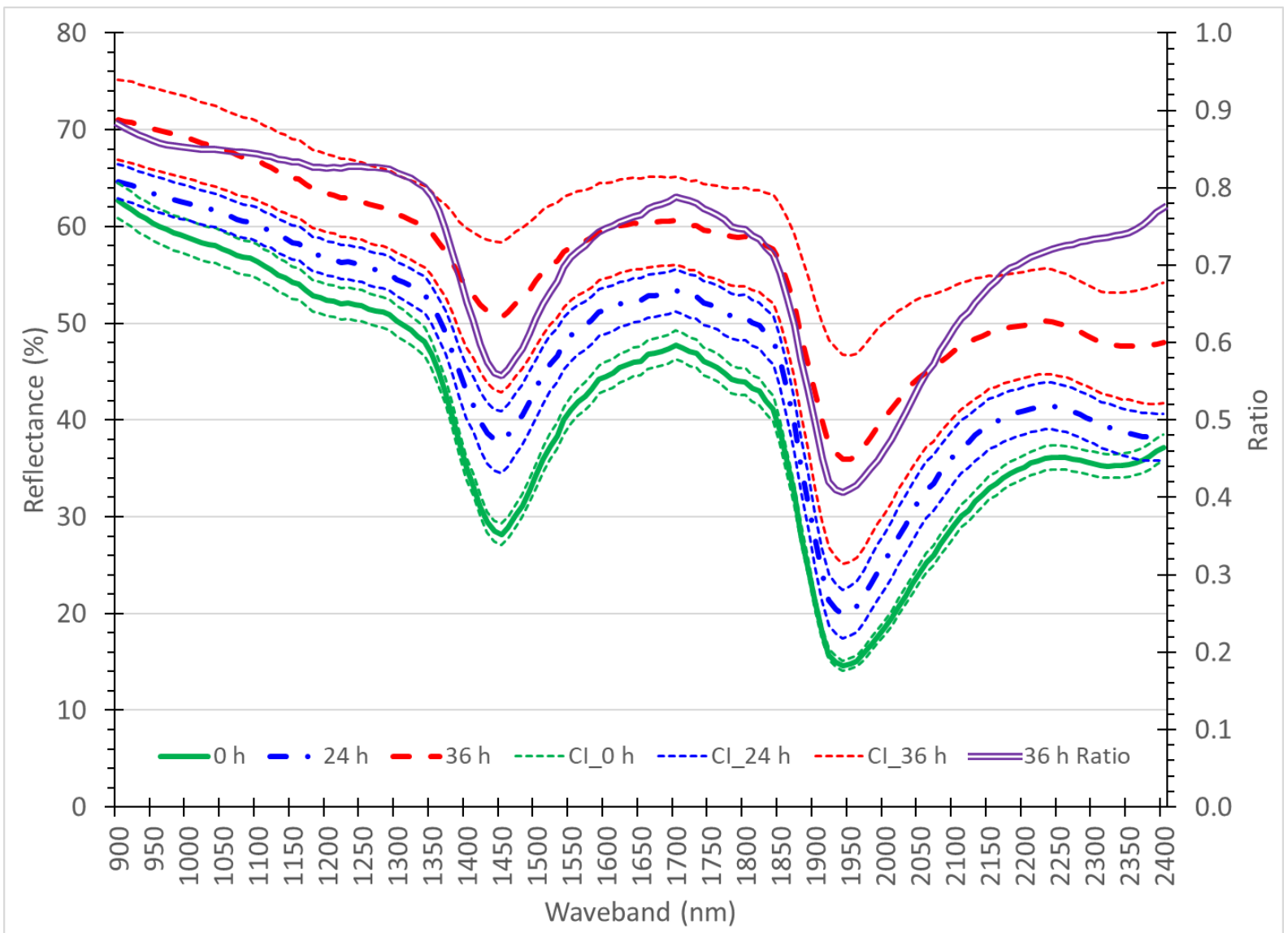

FIGURE 5. Reflectance spectra of toxin-treated Pharaoh cultivar at $0 \mathrm{~h}, 24 \mathrm{~h}$ and $36 \mathrm{~h}$, with $95 \%$ confidence intervals (CI), and ratio of $0 \mathrm{~h}$ reflectance to each of $24 \mathrm{~h}$ and $36 \mathrm{~h}$ reflectance on the secondary $\mathrm{y}$-axis.

These results are similar to those of a previous study (Al-Ahmadi et al., 2018), with the exception that seedlings were not too wilted to be handled until $36 \mathrm{~h}$ after toxin treatment. This increase in time from 24 to $36 \mathrm{~h}$ can most likely be attributed to variations in toxin strength between the two studies. The fungal filtrate was prepared similarly in both studies; however, the activity of the filtrate in the different experiments could be slightly different between experiments. The fungal toxins could have formed at different rates in the media for the two experiments and could have been slightly lower than that used in the previous study by Al-Ahmadi et al. (2018).

The ratio of $0 \mathrm{~h}$ reflectance to $36 \mathrm{~h}$ reflectance was 0.41 at $1940 \mathrm{~nm}$, which is slightly higher than the corresponding ratio of 0.32 observed after $24 \mathrm{~h}$ in a previous study (Al-Ahmadi et al., 2018). Although plants were too wilted for handling without damage at $36 \mathrm{~h}$ after treatment, there may have been an interim time that would have 
allowed leaf handling and an even greater increase in HS reflectance. A disadvantage is that the exact ratios derived from one experiment cannot be compared directly to those from another experiment, but the relative response of cultivars may be consistent. This may require that each experiment uses one of the same cultivars as a type of control. If the toxicity of different batches of $M$. phaseolina toxin can be standardized, a standard period and direct comparison of ratios among experiments may be attainable.

Spencer seedlings were also affected by the toxin, but not to the extent of the Pharaoh seedlings. There was a noted variation in the response, as seen in Figure 6, and in the wider error bands (Fig. 7) for 24 and $36 \mathrm{~h}$. The mean reflectance curves at 24 and $36 \mathrm{~h}$ were slightly higher than those at $0 \mathrm{~h}$. However, the Spencer cultivar did not exhibit any significant differences $\left(F_{(2,21)}, p>0.05\right)$ across the entire 900-2400 nm spectrum among measurement events among 0,24 , and $36 \mathrm{~h}$. The ratios of $0 \mathrm{~h}$ reflectance to 36 $\mathrm{h}$ reflectance dropped to 0.88 in the $1910-1940 \mathrm{~nm}$ range and was considerably higher than that of Pharaoh seedlings (0.41).

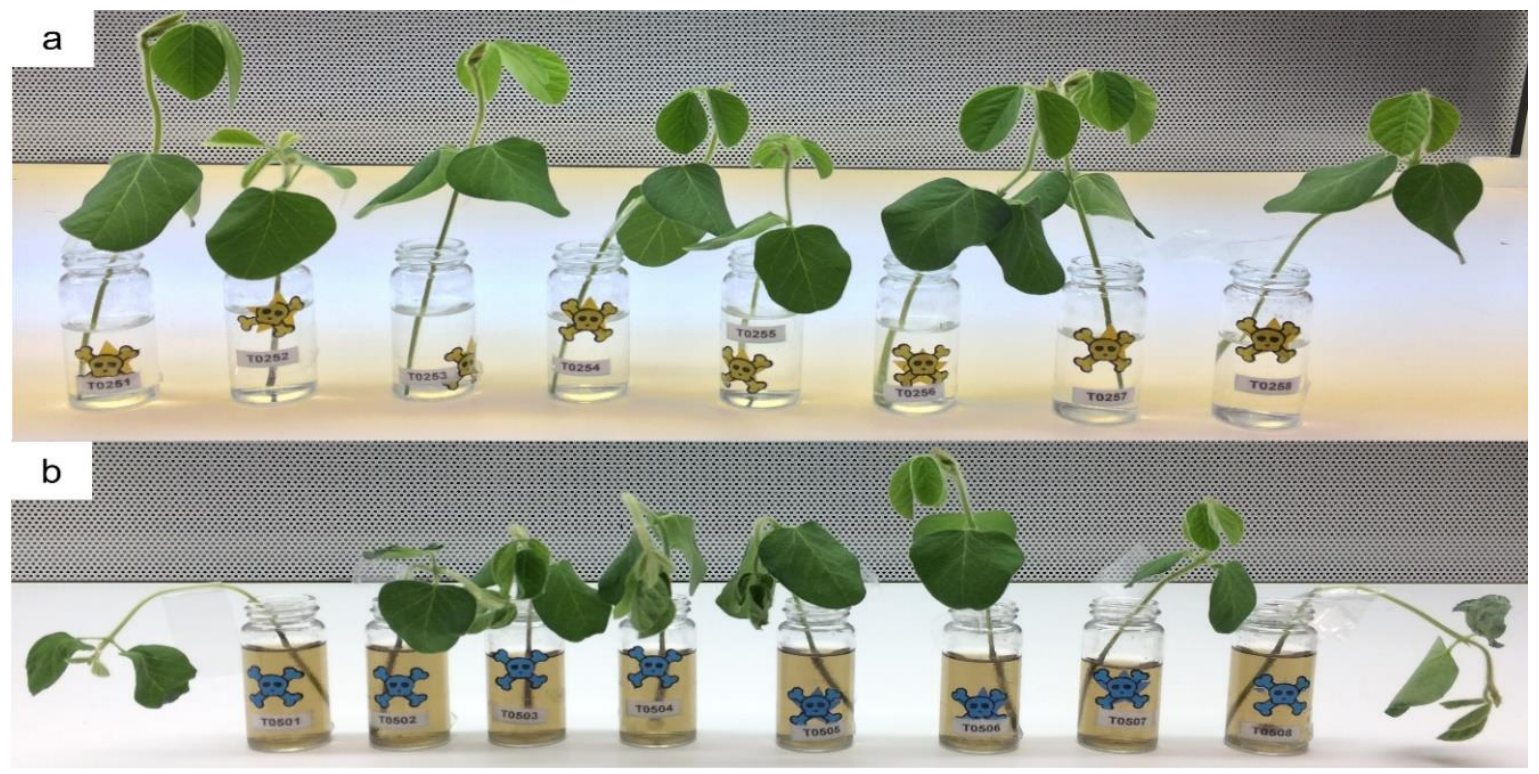

FIGURE 6. Spencer cultivar at $36 \mathrm{~h}$ after toxin treatment illustrating the relative health of a) controls and b) toxin-treated seedlings.

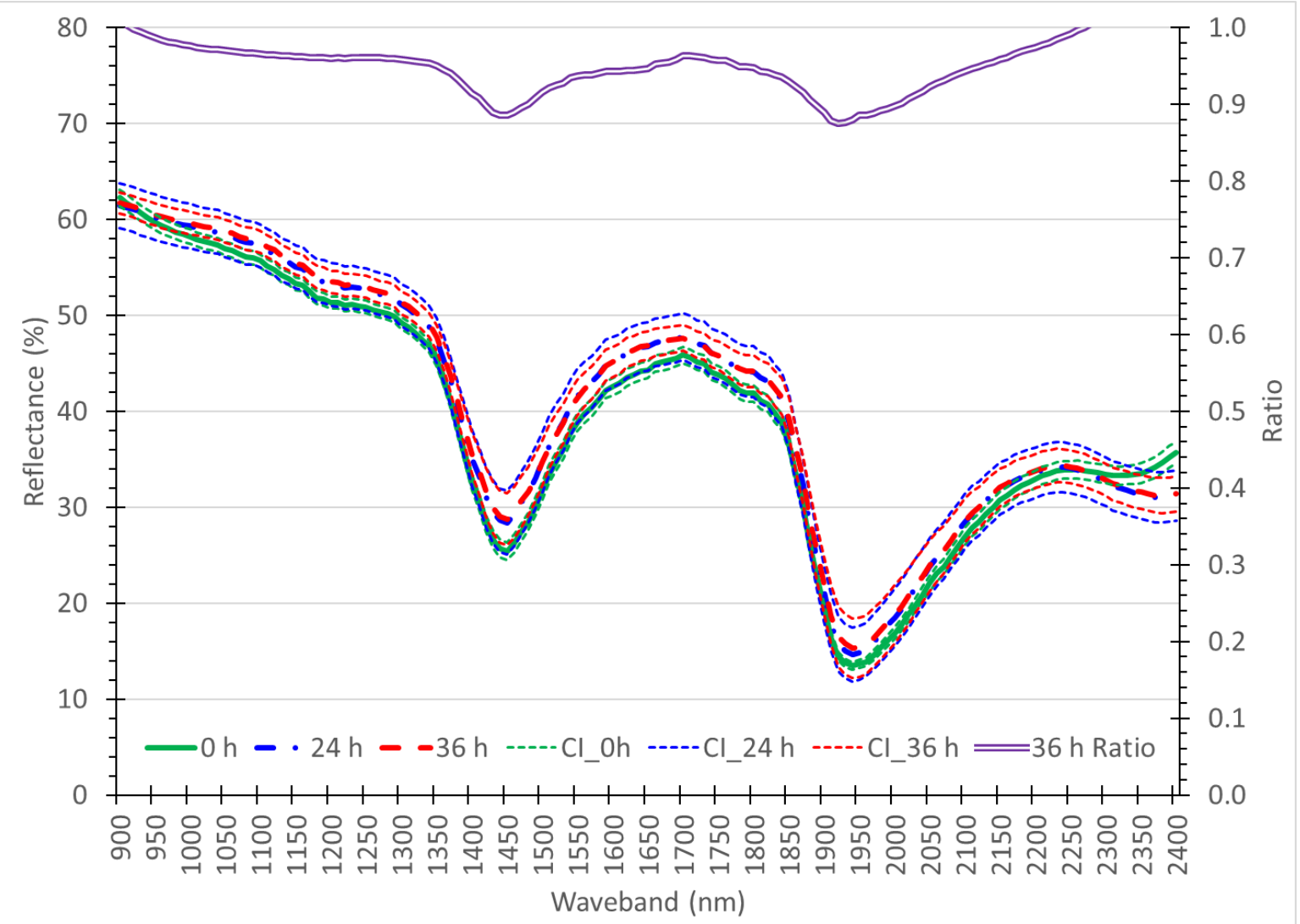

FIGURE 7. Reflectance spectra of toxin-treated Spencer cultivar at $0 \mathrm{~h}, 24 \mathrm{~h}$ and $36 \mathrm{~h}$, with $95 \%$ confidence intervals (CI), and ratio of $0 \mathrm{~h}$ reflectance to each of $24 \mathrm{~h}$ and $36 \mathrm{~h}$ reflectance on the secondary $\mathrm{y}$-axis. 
When comparing Pharaoh and Spencer toxin-treated seedlings at $24 \mathrm{~h}$, Pharaoh seedlings had significantly $\left(F_{(1,14)}, p<0.05\right)$ higher reflectance levels than Spencer seedlings in the range of 1130-2400 nm, with highly significant $\left(F_{(1,14)}, p<0.01\right)$ differences in the 1360-1910 $\mathrm{nm}$ and 1980-2400 $\mathrm{nm}$ ranges. At $36 \mathrm{~h}$, the Pharaoh reflectance values were significantly $\left(F_{(1,14)}, p<0.01\right)$ higher across the entire 900-2400 nm range. This increase in reflectance is consistent with the finding of Hunt \& Rock (1989), where reflectance in the range of 780-2500 nm increased with reduced leaf water content, which is consistent with the wilt symptom associated with charcoal rot (Diourte et al., 1995).

\section{CONCLUSIONS}

The results of this study indicate that HS can be used to detect different responses of soybean seedlings to the toxins produced by $M$. phaseolina and causing seedling wilting. The soybean cultivars 'Pharaoh' and 'Spencer' are susceptible and resistant to M. phaseolina, respectively. HS reflectance increased more significantly in the 900-2400 $\mathrm{nm}$ range for the susceptible cultivar.

Regardless of the period used, the ratio $0 \mathrm{~h}$ reflectance to the last reflectance measurement at $1940 \mathrm{~nm}$ showed potential to be used to rate soybeans for susceptibility to $M$. phaseolina. While the ratio could be inverted, the current form of the ratio has a practical limit of 1.0 for maximum resistance and a number approaching 0 for maximum susceptibility, with lower ratio values indicating higher susceptibility.

Based on this study and on the results of Al-Ahmadi et al. (2018), ratios above 0.8 indicate cultivars that have low susceptibility to charcoal rot toxin, while ratios below 0.5 indicate high susceptibility to the toxins. Additional experiments using cultivars with more variation in susceptibility would be needed to refine the interpretation of ratio values.

\section{REFERENCES}

Al-Ahmadi AH, Subedi A, Wang G, Choudhary R, Fakhoury A, Watson DG (2018) Detection of charcoal rot (Macrophomina phaseolina) toxin effects in soybean (Glycine max) seedlings using hyperspectral spectroscopy. Computers and Electronics in Agriculture 150:188-195. DOI: https://doi.org/10.1016/j.compag.2018.04.013

Bauer ME (1985) Spectral Inputs to Crop Identification and Condition Assessment. Proceedings of the IEEE. DOI: https://doi.org/10.1109/PROC.1985.13238

Bohnenkamp D, Kuska MT, Mahlein AK, Behmann J (2019) Hyperspectral signal decomposition and symptom detection of wheat rust disease at the leaf scale using pure fungal spore spectra as reference. Plant Pathology 68:1188-1195. DOI: https://doi.org/10.1111/ppa.13020

Cao X, Luo Y, Zhou Y, Fan J, Xu X, West JS, Duan X, Cheng D (2015) Detection of powdery mildew in two winter wheat plant densities and prediction of grain yield using canopy hyperspectral reflectance. PLoS ONE 10 (3)e0121462. DOI:

https://doi.org/10.1371/journal.pone.0121462
Coser SM, Reddy RVC, Zhang J, Mueller DS, Mengistu A, Wise KA, Allen TW, Singh A, Singh AK (2017) Genetic architecture of charcoal rot (Macrophomina phaseolina) resistance in soybean revealed using a diverse panel. Frontiers in Plant Science 8: DOI: https://doi.org/10.3389/fpls.2017.01626

Diourte M, Starr JL, Jeger MJ, Stack JP, Rosenow DT (1995) Charcoal rot Macrophomina phaseolina resistance and the effects of water stress on disease development in sorghum. Plant Pathology 44:196-202. DOI: https://doi.org/10.1111/j.1365-3059.1995.tb02729.x

Fehr WR, Caviness CE, Burmood DT, Pennington JS (1971) Stage of development descriptions for soybeans, Glycine max (L.) Merrill 1. Crop Science 11:929-931. DOI: https://doi.org/10.2135/cropsci1971.0011183x001100060051x

Fletcher RS, Smith JR, Mengistu A, Ray JD (2014) Relationships between microsclerotia content and hyperspectral reflectance data in soybean tissue infected by Macrophomina phaseolina. American Journal of Plant Sciences 05:3737-3744. DOI: https://doi.org/10.4236/ajps.2014.525390

Gold KM, Townsend PA, Herrmann I, Gevens AJ (2019) Investigating potato late blight physiological differences across potato cultivars with spectroscopy and machine learning. Plant Science 295. DOI:

https://doi.org/10.1016/j.plantsci.2019.110316

Haider Khan I, Liu H, Cheng T, Tian Y, Cao Q, Zhu Y, Cao W, Yao X (2018) Detection of wheat powdery mildew based on hyperspectral reflectance through SPA and PLS-LDA. International Journal of Precision Agricultural Aviation 1:13-22. DOI: https://doi.org/10.33440/j.ijpaa.20200301.67

Hemmati P, Zafari D, Mahmoodi SB, Hashemi M, Gholamhoseini M, Dolatabadian A, Ataei R (2018) Histopathology of charcoal rot disease (Macrophomina phaseolina) in resistant and susceptible cultivars of soybean. Rhizosphere 7:27-34. DOI:

https://doi.org/10.1016/j.rhisph.2018.06.009

Hennessy A, Clarke K, Lewis M (2020) Hyperspectral classification of plants: a review of waveband selection generalisability. Remote Sensing 12(1):113. DOI: https://doi.org/10.3390/rs12010113

Hunt ER, Rock BN (1989) Detection of changes in leaf water content using near- and middle-infrared reflectances. Remote Sensing of Environment 30:43-54. DOI: https://doi.org/10.1016/0034-4257(89)90046-1

Lee S, Van K, Sung M, Nelson R, LaMantia J, McHale LK, Mian MAR (2019) Genome-wide association study of seed protein, oil and amino acid contents in soybean from maturity groups I to IV. Theoretical and Applied Genetics 132:1639-1659. DOI: https://doi.org/10.1007/s00122-01903304-5

Luna MPR, Mueller D, Mengistu A, Singh AK, Hartman GL, Wise KA (2017) Advancing our understanding of charcoal rot in soybeans. Journal of Integrated Pest Management 8(1). DOI:

https://doi.org/10.1093/jipm/pmw020 
Mahlein AK (2016) Plant disease detection by imaging sensors - Parallels and specific demands for precision agriculture and plant phenotyping. Plant Disease 100:241-254.

Mengistu A, Smith JR, Ray JD, Bellaloui N (2011) Seasonal progress of charcoal rot and its impact on soybean productivity. Plant Disease 95:1159-1166. DOI: https://doi.org/10.1094/PDIS-02-11-0100

Meyer WA (1974) Factors affecting charcoal rot of soybean seedlings. Phytopathology 64:845. DOI: https://doi.org/10.1094/phyto-64-845

Mo C, Kim G, Kim MS, Lim J, Lee K, Lee WH, Cho BK (2017) On-line fresh-cut lettuce quality measurement system using hyperspectral imaging. Biosystems Engineering 156:38-50. DOI:

https://doi.org/10.1016/j.biosystemseng.2017.01.005

Nagasubramanian K, Jones S, Sarkar S, Singh AK, Singh A, Ganapathysubramanian B (2018) Hyperspectral band selection using genetic algorithm and support vector machines for early identification of charcoal rot disease in soybean stems. Plant Methods 14:86. DOI: https://doi.org/10.1186/s13007-018-0349-9

Pawlowski ML, Hill CB, Hartman GL (2015) Resistance to charcoal rot identified in ancestral soybean germplasm. Crop Science 55:1230-1235. DOI:

https://doi.org/10.2135/cropsci2014.10.0687

Pearson CAS (1984) Colonization of soybean roots by Macrophomina phaseolina. Plant Disease 68:1086. DOI: https://doi.org/10.1094/pd-69-1086

Porker K, Zerner M, Cozzolino D (2017) Classification and authentication of barley (Hordeum vulgare) malt varieties: combining attenuated total reflectance midinfrared spectroscopy with chemometrics. Food Analytical Methods 10:675-682. DOI: https://doi.org/10.1007/s12161-016-0627-y

Twizeyimana M, Hill CB, Pawlowski M, Paul C, Hartman GL (2012) A cut-stem inoculation technique to evaluate soybean for resistance to Macrophomina phaseolina. Plant Disease 96:1210-1215. DOI: https://doi.org/10.1094/PDIS02-12-0126-RE

Wang L, Li J, Qin H, Xu J, Zhang X, Huang L (2019) Selecting near-infrared hyperspectral wavelengths based on one-way ANOVA to identify the origin of Lycium barbarum. In: International Conference on High Performance Big Data and Intelligent Systems, HPBD and IS 2019. p122-125.

Wee C Do, Hashiguchi M, Ishigaki G, Muguerza M, Oba C, Abe J, Harada K, Akashi R (2018) Evaluation of seed components of wild soybean (Glycine soja) collected in Japan using near-infrared reflectance spectroscopy. Plant Genetic Resources: Characterisation and Utilisation 16(2). DOI: https://doi.org/10.1017/S1479262116000472

Whetton RL, Hassall KL, Waine TW, Mouazen AM (2018) Hyperspectral measurements of yellow rust and fusarium head blight in cereal crops: Part 1: Laboratory study. Biosystems Engineering 166:101-115. DOI: https://doi.org/10.1016/j.biosystemseng.2017.11.008 